\title{
DESENVOLVIMENTO E AVALIAÇÃO DE RÉPLICAS EM RESINAS DE BENS DO PATRIMÔNIO CULTURAL COM USO DE DIGITALIZAÇÃO 3D E FABRICAÇÃO DIGITAL
}

Development and evaluation of resins replicas of cultural heritage using 3D scanning and digital fabrication

\section{Carolina de Freitas Bonfada', Aline Reis Kauffmann', Fabio Pinto da Silva'}

RESUMO: O uso das novas tecnologias digitais viabiliza estratégias essenciais para a documentação e preservação do patrimônio cultural. A utilização da digitalização 3D permite o registro digital de obras do patrimônio, ao passo que esses registros possibilitam o desenvolvimento de análises e estudos. As digitalizações podem ainda ser utilizadas para a produção de réplicas fidedignas de obras danificadas ou furtadas. Este trabalho tem por objetivo a análise dimensional de réplicas produzidas em resinas a partir do uso da digitalização 3D em conjunto com técnicas de fabricação digital. Nesse sentido, foi adotada uma metodologia de pesquisa experimental, a partir de um estudo de caso. Para tanto, as placas em bronze do monumento a Bento Gonçalves (Porto Alegre, RS) foram digitalizadas em 3D e um trecho de uma delas foi selecionado para a realização de ensaios de fabricação digital. Foram produzidas duas peças, uma pelo processo de usinagem por comando numérico computadorizado (CNC) e outra por impressão 3D por filamento fundido (FFF). A peça usinada foi selecionada para a construção de um molde em silicone para posterior produção das réplicas em resina. Todas as etapas do processo de produção das réplicas foram digitalizadas para a realização de análise dimensional. Os resultados demonstraram que a usinagem CNC é o processo mais preciso dimensionalmente para a produção das réplicas das placas. Entre os materiais ensaiados, a resina de poliéster cristal é a mais apropriada para produção de uma eventual peça de reposição.

PALAVRAS-CHAVE: Réplicas; Patrimônio Cultural; Digitalização Tridimensional; Usinagem CNC; Impressão 3D.

\begin{abstract}
The use of new digital technologies can enable important strategies for documenting and preserving cultural heritage. The use of $3 \mathrm{D}$ digitization allows the digital registration of heritage objects. These records enable the development of analyzes and studies. Scans can also be used to produce replicas of damaged or stolen objects. This paper aims at the dimensional analysis of replicas produced in resins from 3D scanning in conjunction with digital fabrication techniques. In this sense, an experimental research methodology was adopted, based on a case study. Therefore, bronze plaques of the Monument to Bento Gonçalves (Porto Alegre, RS, Brazil) were digitized and a section of one of them was selected for the achievement of digital manufacture tests. Two parts were produced, one by computerized numerical command (CNC) machining and other by 3D printing by fused filament fabrication (FFF). The machined part was selected to create a silicone mold for subsequent production of the resin replicas. All steps of the replication process were 3D scanned for dimensional analysis. The results demonstrated that CNC machining is the most dimensionally accurate process for the production of the plaques replicas. Among the materials tested, the crystal polyester resin is most suitable for the production of a possible replacement part.
\end{abstract}

KEYWORDS: Replicas; Cultural Heritage; Three-dimensional scanning; CNC machining; 3D printing.

How to cite this article:

BONFADA, C. F.; KAUFFMANN, A. R.; SILVA, F. P. Desenvolvimento e avaliação de réplicas em resinas de bens do patrimônio cultural com uso de digitalização 3D e fabricação digital. Gestão e Tecnologia de Projetos, São Carlos, v.15, n.1, p.42-53, jan.2020. http://dx.doi.org/10.116/gtp.v14i1.152672

Fonte de financiamento:

CAPES E CNPO

Conflito de interesse:

Submetido em: 12/12/2018

Aceito em: 29/06/2019 


\section{INTRODUÇÃO}

O bronze é um material habitualmente empregado em monumentos, bustos, esculturas e placas expostas em locais públicos. No Brasil, os monumentos contendo elementos compostos por esse material vêm sendo alvos de furtos devido ao seu alto valor comercial (FRAZÃO, 2018; REYS et al., 2008; TILL, 2002). Após serem furtadas, algumas peças são recriadas, usualmente, com a utilização de materiais alternativos ao bronze, como resinas, para impedir novas ações de furto. Na cidade de Porto Alegre, quando necessário, as peças desenvolvidas para reposição são feitas com moldes confeccionados por meio de réplicas esculpidas manualmente. Os escultores utilizam fotografias para desenvolver uma releitura da obra (BENEDETTI, 2016). As reproduções são elaboradas conforme a interpretação visual e habilidades do artista, e acabam por diferir da forma e técnicas correspondentes ao objeto original.

A ocorrência de acidentes, que podem ocasionar a perda de peças importantes de acervos, ou mesmo a exposição às intempéries, requerem a aquisição das informações de textura e volumetria de peças do patrimônio cultural para posterior confecção de uma réplica. Identifica-se, então, a necessidade de elaboração de um processo para reposição, que mantenha a volumetria da peça original e permita a maior aproximação possível em relação ao objeto substituído.

As novas tecnologias digitais incluem processos tanto para aquisição de dados em três dimensões, como a digitalização 3D, quanto para fabricação digital, como a impressão 3D e a usinagem por comando numérico computadorizado (CNC). A digitalização 3D permite o registro das obras, salvaguardando as informações de textura e volumetria que as constituem. Esses registros podem ser utilizados para a produção de modelos virtuais das peças visando a disponibilização em repositórios online (MUNIZ et al., 2018). O alinhamento da digitalização 3D com a fabricação digital pode aprimorar a preservação dos bens do patrimônio cultural, possibilitando o desenvolvimento de recursos para a promoção da educação patrimonial. Os modelos geométricos podem ainda ser adaptados e utilizados na fabricação digital de recursos tridimensionais para possibilitar a compreensão das peças por pessoas com deficiência visual (D'AGNANO et al., 2015; BALLARIN et al., 2018).

Réplicas físicas fidedignas podem fomentar estudos para restauração ou mesmo para a reposição de obras eventualmente furtadas ou desaparecidas. Considerando a restrição de materiais utilizados para fabricação digital, as peças assim obtidas podem ser empregadas para produzir moldes. Deste modo, pode-se aumentar a qualidade de peças produzidas com materiais e técnicas já utilizados por artistas e restauradores, seja via fundição de metais, como o bronze, ou vazamento de resinas, as quais permitem imitar a aparência de diferentes materiais.

Nesse contexto, o presente estudo é fundamentado na compreensão de que a digitalização tridimensional e as ferramentas de fabricação digital podem auxiliar na preservação das obras, viabilizando ações para promover o acesso, a preservação e a reconstrução de bens do patrimônio cultural. Contudo, não são encontrados muitos dados na literatura acerca da precisão dimensional que pode ser alcançada com a combinação dessas tecnologias entre si ou com técnicas manuais. Assim, se tem por objetivo o desenvolvimento e a análise dimensional da produção de réplicas fidedignas do monumento a Bento Gonçalves, um bem cultural da cidade de Porto Alegre, a partir de técnicas de digitalização 3D, impressão tridimensional por filamento fundido (FFF) e usinagem CNC. Ainda, contemplou-se o desenvolvimento e a análise dimensional de peças moldadas em resinas a partir de um dos modelos obtidos por fabricação digital. 


\section{Digitalização 3D do patrimônio cultural}

A utilização de tecnologias digitais desenvolveu-se exponencialmente nos últimos anos. $\mathrm{O}$ uso dessas ferramentas proporciona uma contribuição fundamental para a documentação, análise e posterior utilização do acervo cultural para fins diversos como: pesquisa, diagnóstico e preservação do patrimônio cultural. O desenvolvimento de instrumentos e métodos, bem como a disseminação de técnicas como a digitalização 3D, vêm estabelecendo novas possibilidades e cenários nesse campo (BALLETTI et al., 2017). Segundo Adami et al. (2015), o evidente desenvolvimento no campo da digitalização do patrimônio cultural está relacionado à maior conscientização das funções econômicas e culturais desses itens, bem como à sua caracterização como elemento de reconhecimento e compartilhamento.

O estudo "The Digital Michelangelo Project: 3D Scanning of Large Statues” é um exemplo da utilização da digitalização tridimensional para registro digital do patrimônio histórico. Os autores apresentam o sistema de hardware e software desenvolvido pela equipe para possibilitar a digitalização da forma e da cor de grandes objetos frágeis em condições não-laboratoriais. Para demonstrar o funcionamento do sistema elaborado, foram digitalizados fragmentos do Plano de Mármore (Forma Urbis Romae), os interiores de dois edifícios e dez estátuas de Michelangelo, dentre elas, a famosa figura de David (LEVOY et al., 2000).

Outro trabalho desenvolvido nesse campo, foi a digitalização do busto de terracota de Francesco II Gonzaga, no Museu da Cidade de Mântua, desenvolvida utilizando um scanner de triangulação e fotogrametria digital. O objetivo dos autores foi desenvolver uma cópia digital de alta fidelidade, possibilitando a documentação de um bem cultural e a reprodução física, demonstrando a importância da réplica impressa em 3D (ADAMI et al., 2015).

A digitalização tridimensional combinada com os processos de fabricação digital possibilita o desenvolvimento de réplicas fidedignas. Essas peças podem ser desenvolvidas para permitir e facilitar o acesso a elementos do patrimônio cultural por pessoas com deficiência visual (BALLARIN et al., 2018), assim como para preservação de um elemento histórico exposto a intempéries ou mesmo para difusão do patrimônio cultural.

Rossetti et al. (2018) desenvolveram um modelo interativo da Praça dos Milagres, em Pisa, utilizando a prototipagem rápida. Os modelos foram impressos tridimensionalmente e compõem um sistema que tem como objetivo permitir que pessoas com deficiência visual compreendam elementos de locais culturais, praças, prédios, incluindo cúpulas e pequenos detalhes não acessíveis pelo toque. O sistema combina os modelos táteis e a audiodescrição para permitir a utilização autônoma.

Em um estudo desenvolvido no sítio arqueológico de Ulaan Tolgoi, na Mongólia, Beaubien e Karas (2007) realizaram a digitalização de esculturas em rochas. Os modelos digitalizados foram processados para a produção de réplicas, sendo uma delas produzida pelo processo de usinagem CNC.

Nesse contexto, é possível verificar que o uso das tecnologias aqui apresentadas auxilia a preservação do patrimônio cultural. A digitalização tridimensional possibilita o desenvolvimento de um modelo digital para salvaguardar a peça. Este método permite ainda a realização de análises dimensionais precisas e, quando alinhado aos processos de fabricação digital, viabiliza a produção de réplicas fidedignas. Logo, essas tecnologias podem ser utilizadas para o desenvolvimento e análise do processo de produção de réplicas do patrimônio cultural. 


\section{MATERIAIS E MÉTODOS}

Para realização do estudo, foi adotada uma metodologia de pesquisa experimental, a partir de um estudo de caso. Os procedimentos utilizados são apresentados na Figura 1 e descritos a seguir.

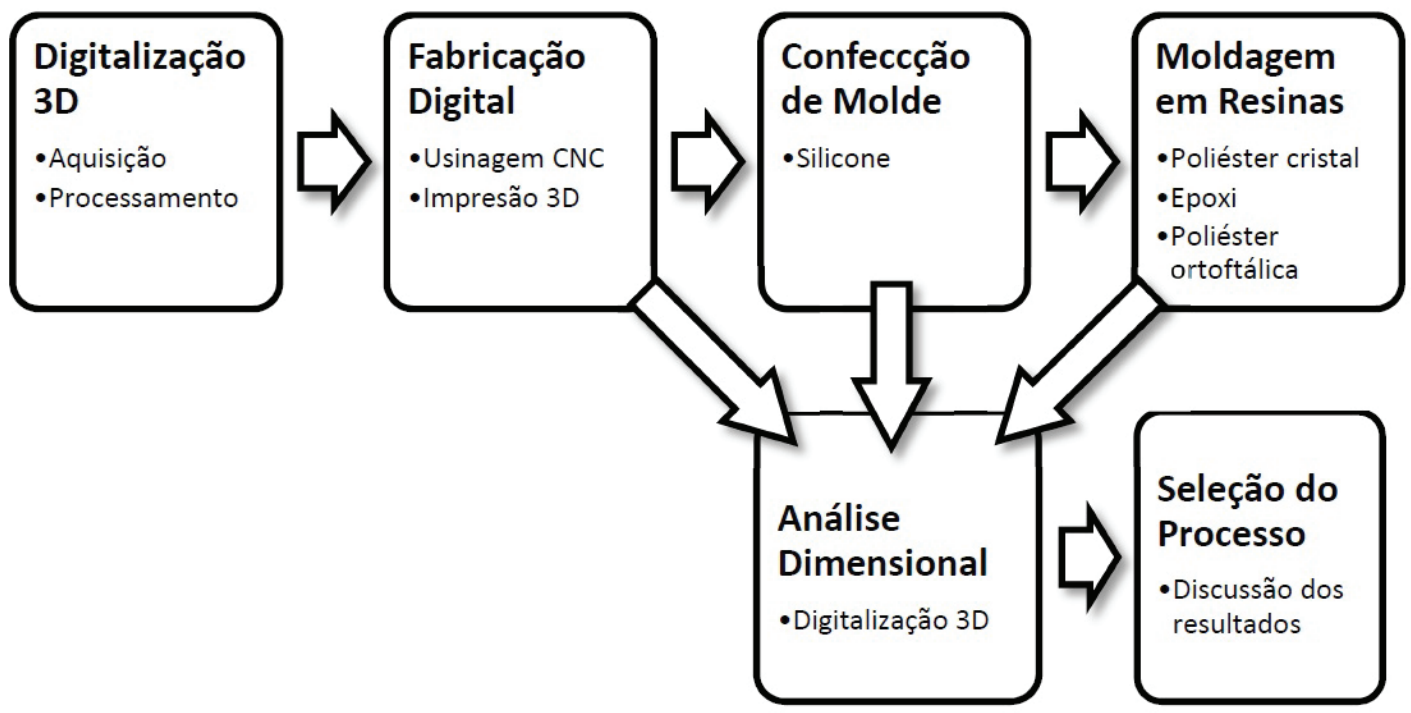

Figura 1: Procedimentos utilizados para realização do trabalho

Fonte: Elaborado pelos autores.

O objeto escolhido para desenvolvimento deste estudo foi uma obra do patrimônio cultural da cidade de Porto Alegre, o monumento a Bento Gonçalves. De autoria do escultor Antônio Caringi, a obra foi selecionada devido aos ataques já sofridos e por conter elementos em bronze suscetíveis ao furto. O monumento é composto por um pedestal de concreto e granito, com nove metros de altura, contendo uma escultura equestre no topo e duas placas em bronze nas laterais com $1.370 \times 1.050 \mathrm{~mm}$. O mesmo foi inaugurado em 15 janeiro de 1936, durante a exposição do centenário da revolução farroupilha (SPALDING, 1967).

Em 1941, o monumento foi realocado, durante uma revitalização urbana da cidade de Porto Alegre, para ser um destaque na junção das avenidas Azenha e João Pessoa. Assim, foi originada a praça Piratini, contendo espelhos d'água, com esguichos e iluminação. Para isso, o monumento passou por uma remodelagem, ganhou um pedestal mais elevado e recebeu uma frase na frente do pedestal: "Compatriotas! O nome da pátria nunca soou em vão aos meus ouvidos.” (ALVES, 2004).

Infortunadamente, ambas as placas que integravam o monumento foram furtadas após a realização das digitalizações 3D (ESTÁTUA..., 2017; VARGAS, 2017). A Figura 2A exibe o monumento em novembro de 2016 contendo as duas placas em bronze. A Figura 2B exibe o monumento em março de 2017, após o furto das placas. 

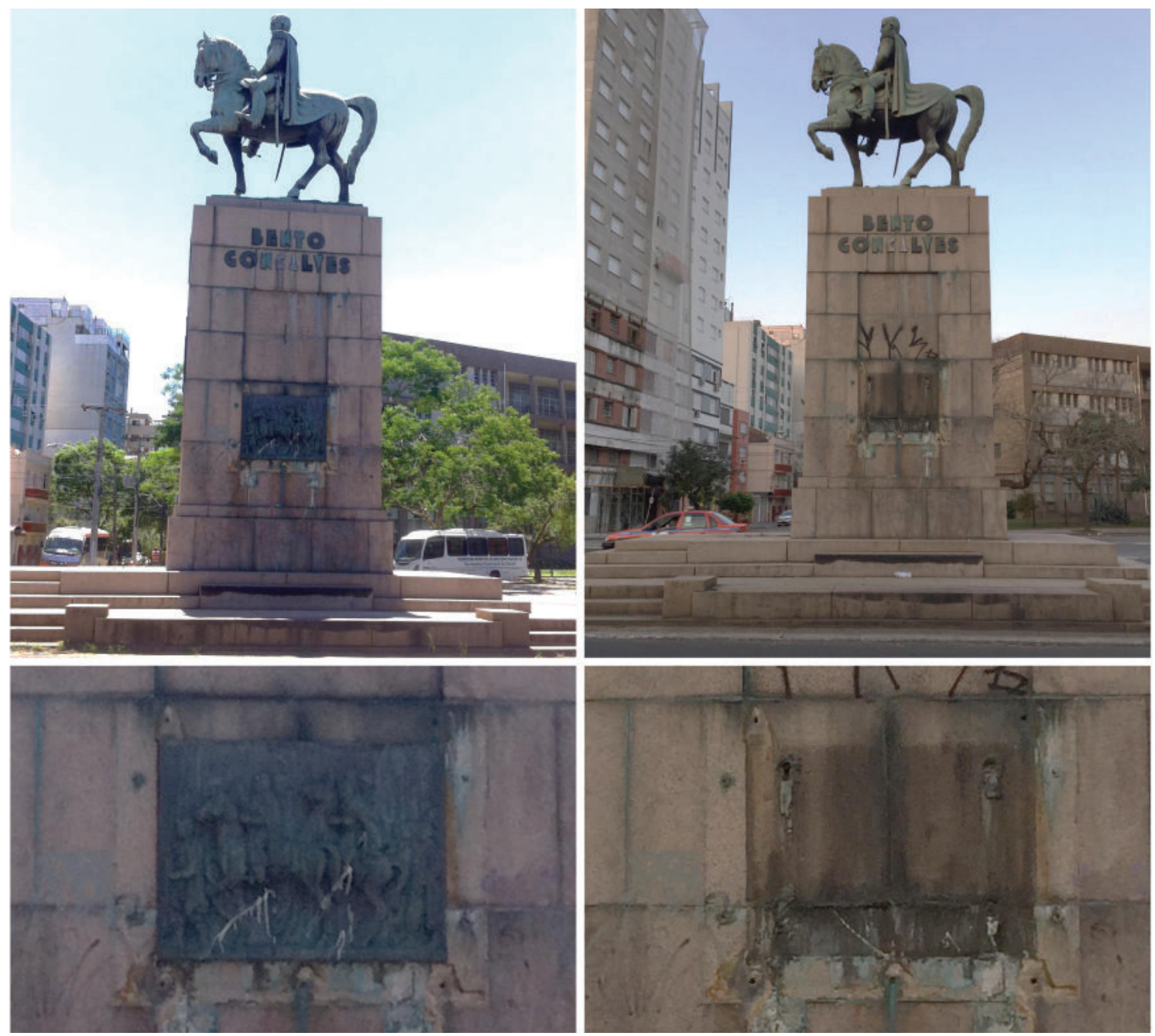

Figura 2: Monumento a Bento Gonçalves, vista da Av. Azenha, Porto Alegre - RS. A) situação em novembro de 2016; B) situação em março de 2017.

Fonte: Elaborado pelos autores.

\section{Digitalização 3D}

Para obtenção dos dados digitais do monumento foi realizada a digitalização tridimensional das duas placas laterais utilizando um escâner de luz estruturada Artec EVA. O processamento inicial do modelo foi realizado no software Artec Studio. As nuvens de pontos obtidas foram filtradas, alinhadas e unidas formando uma malha triangular. Posteriormente, o arquivo resultante do processamento inicial foi manipulado no software Geomagic Studio, para ajuste da malha e preparação para fabricação digital.

Após a digitalização e o tratamento da malha, um trecho do arquivo digital, contendo detalhes e profundidades distintas de uma das placas, foi selecionado para realização dos ensaios de fabricação digital. A parte escolhida possui as dimensões de 330 × $210 \mathrm{~mm}$, representando cerca de 5\% da superfície total da placa, e está voltada para a avenida Azenha (Figura 2A). A Figura 3 apresenta o arquivo resultante dos processamentos da digitalização 3D. O trecho selecionado para o desenvolvimento dos ensaios de fabricação digital está destacado na cor cinza. 


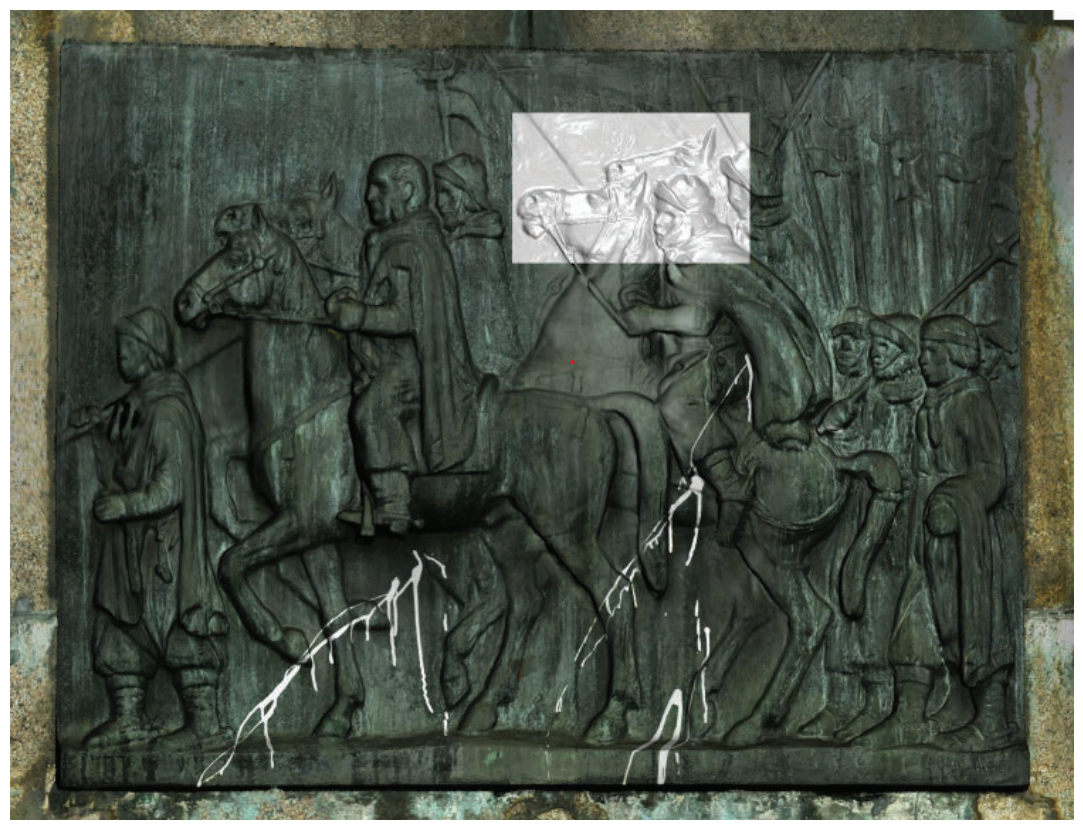

Figura 3: Obra digitalizada com destaque ao trecho escolhido para realização dos ensaios.

Fonte: Elaborado pelos autores.

\section{Fabricação Digital}

Para os ensaios de fabricação digital foram adotadas as técnicas de usinagem CNC e impressão 3D por FFF. Após a fabricação, as peças foram digitalizadas tridimensionalmente, para posterior análise dimensional e seleção do processo de desenvolvimento da peça que daria origem ao molde.

O equipamento utilizado para a usinagem foi o Digimill $3 D$, do Laboratório de Design e Seleção de Materiais (LDSM), da Universidade Federal do Rio Grande do Sul (UFRGS). O material utilizado para esse procedimento foi o Ren Shape 460 (à base de resina de poliuretano). A programação do procedimento foi realizada no software Edgecam, seguindo os parâmetros: velocidade de avanço de $4.000 \mathrm{~mm} / \mathrm{min}$; rotação $12.000 \mathrm{rpm}$; profundidade de corte de $2 \mathrm{~mm}$; e penetração de trabalho $50 \%$ para a etapa de desbaste e de $10 \%$ para acabamento. Primeiro foi realizada a etapa de faceamento nas duas faces do bloco e subsequentemente a etapa de desbaste, ambas realizadas com uma fresa reta de $10 \mathrm{~mm}$ de diâmetro. $\mathrm{O}$ acabamento foi feito com uma fresa esférica de diâmetro $6 \mathrm{~mm}$. A peça usinada foi realizada em três horas e quarenta minutos.

A fabricação por impressão 3D por FFF foi desenvolvida no equipamento $3 D$ Cloner DH. O código para a impressão foi gerado no software ClonerGen3D. O modelo STL foi importado e foram aplicados os seguintes parâmetros de impressão: altura de camada $0,25 \mathrm{~mm}$ e $5 \%$ de preenchimento em formato retilíneo. A peça foi impressa em filamento de Poli (Ácido Lático), PLA, de $1,75 \mathrm{~mm}$ de diâmetro, na temperatura de $205^{\circ} \mathrm{C}$. $\mathrm{O}$ tempo de impressão foi de dezoito horas e quarenta e quatro minutos.

As duas peças fabricadas foram digitalizadas tridimensionalmente para posterior desenvolvimento da análise dimensional. De acordo com a análise, a peça resultante do processo de usinagem $\mathrm{CNC}$ foi a selecionada para o desenvolvimento do molde necessário para a produção das réplicas, conforme melhor detalhado nos resultados. 


\section{Confecção de molde e moldagem em resinas}

Uma caixa em MDF, nas dimensões de 350 x 230 x 60 mm foi construída para a fabricação do molde de silicone. Essas dimensões foram adotadas para permitir uma folga de $10 \mathrm{~mm}$ em relação à peça e às paredes da caixa. O desenvolvimento do molde exigiu a utilização de $5 \mathrm{~kg}$ de silicone de média resistência e $450 \mathrm{~g}$ de catalisador. A peça usinada foi fixada no fundo da caixa. Então, foi aplicado o desmoldante sobre o modelo e, posteriormente, vertido o silicone. Após 48 horas foi realizada a desmoldagem. A Figura 4 ilustra o processo de moldagem.
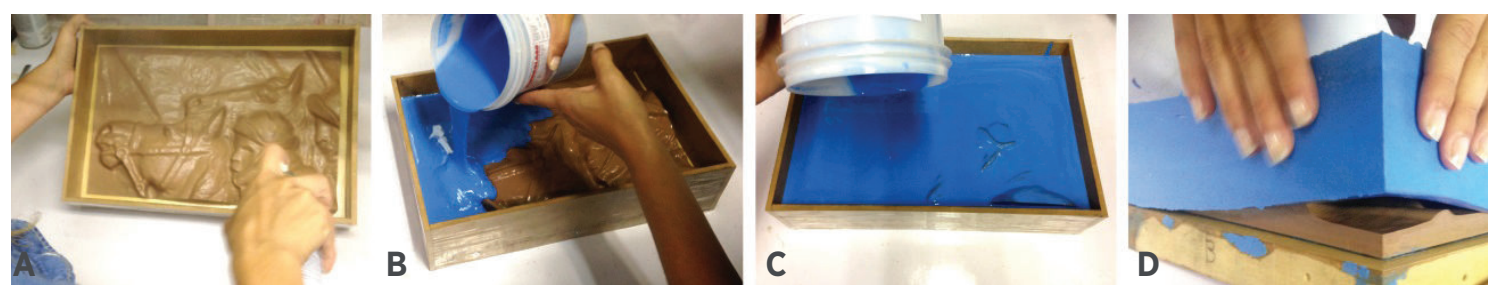

Figura 4: Confecção de molde de silicone. A) Aplicação de desmoldante sobre o modelo; B) e C) Preenchimento com silicone; D) Desmoldagem

Fonte: Elaborado pelos autores.

Para a continuidade do estudo de moldagem, buscaram-se resinas disponíveis no mercado e já utilizadas em trabalhos de confecção de réplicas. Assim, utilizando o molde desenvolvido, foram fabricadas réplicas em três diferentes resinas: poliéster cristal, poliéster ortoftálica e epóxi. Para produção das réplicas, as resinas foram vazadas no molde seguindo as respectivas composições: A) 1,5 kg resina de poliéster cristal e $50 \mathrm{~g}$ de catalisador butanox; B) 1,5 kg de resina de poliéster ortoftálica e $50 \mathrm{~g}$ de catalisador butanox; C) $1 \mathrm{~kg}$ de resina de epóxi e $500 \mathrm{~g}$ de endurecedor. Foram produzidas duas peças em resina poliéster cristal, duas peças em resina epóxi e uma peça em resina ortoftálica, em função da disponibilidade de material. As réplicas obtidas foram desmoldadas após 24 horas, em processo similar ao de moldagem com silicone. Por fim, as peças obtidas foram também submetidas à digitalização 3D para análise dimensional.

\section{Análise Dimensional}

Para análise dimensional, todas as peças obtidas no estudo foram digitalizadas tridimensionalmente no equipamento Digimill 3D. Foi utilizada uma lente de $150 \mathrm{~mm}$, com precisão (eixo z) de 0,035 mm, e a resolução adotada (espaçamento entre pontos nos eixos $\mathrm{x}$ e y) foi de $0,1 \mathrm{~mm}$. $\mathrm{O}$ resultado de cada digitalização é uma nuvem de pontos, no caso específico, aproximadamente 7 milhões de pontos (coordenadas $\mathrm{x}, \mathrm{y}, \mathrm{z}$ ) que descrevem a superfície de uma peça.

As análises foram realizadas no software Geomagic Qualify, no qual as nuvens de pontos foram alinhadas em relação ao modelo original digitalizado (utilizado como referência). A partir desse alinhamento, são calculadas as diferenças entre os pontos da peça analisada e os pontos da peça de referência. O software permite calcular a média e o desvio-padrão entre os milhões de pontos, bem como gerar imagens com mapas de cores para melhor visualização e avaliação dos resultados. 


\section{RESULTADOS}

As peças obtidas pelos processos de usinagem CNC (Figura 5A) e impressão 3D por FFF (Figura 5B), foram digitalizadas e comparadas ao modelo digital resultante do escaneamento da placa originalmente presente no monumento.

A

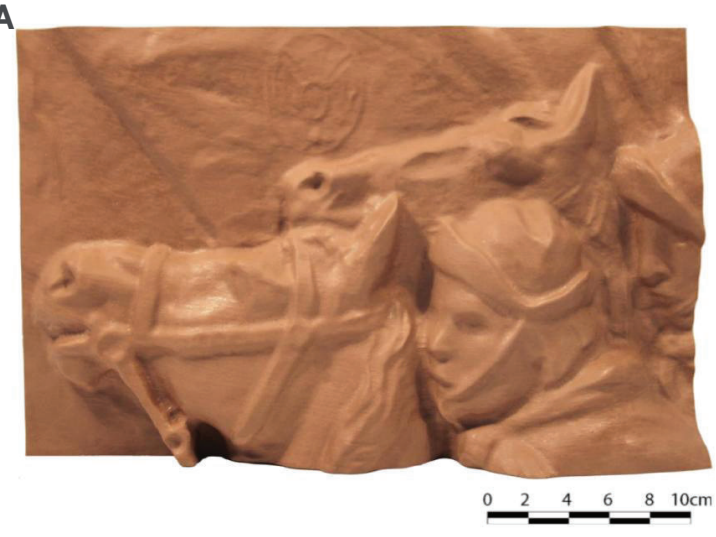

B

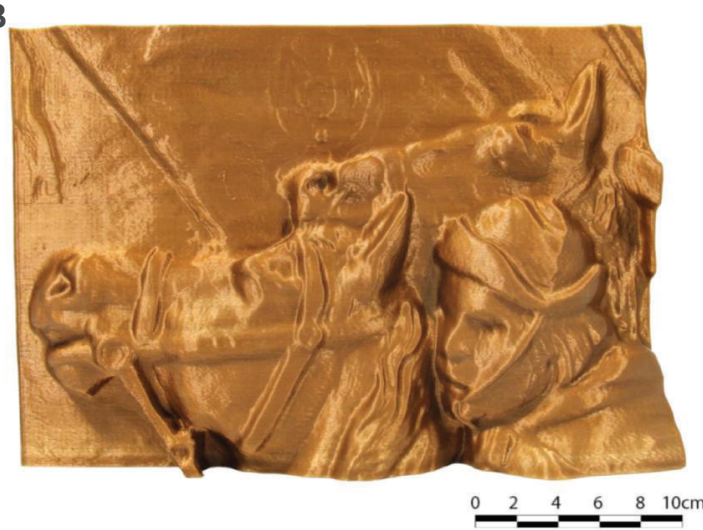

Figura 5: Peças produzidas pelos processos de fabricação digital. A) usinagem CNC; B) impressão 3D por FFF.

Fonte: Elaborado pelos autores.

Para demonstração dos resultados da análise dimensional (Figura 6), o software Geomagic Qualify exibe em tons azulados os pontos localizados abaixo da superfície de referência e em tons avermelhados os pontos acima das dimensões do modelo digital da peça original. Em verde estão as regiões onde ocorreram erros dimensionais menores que $0,2 \mathrm{~mm}$. A área em cinza, na Figura 6B, representa a área que não foi impressa, devido às dimensões da mesa de impressão.
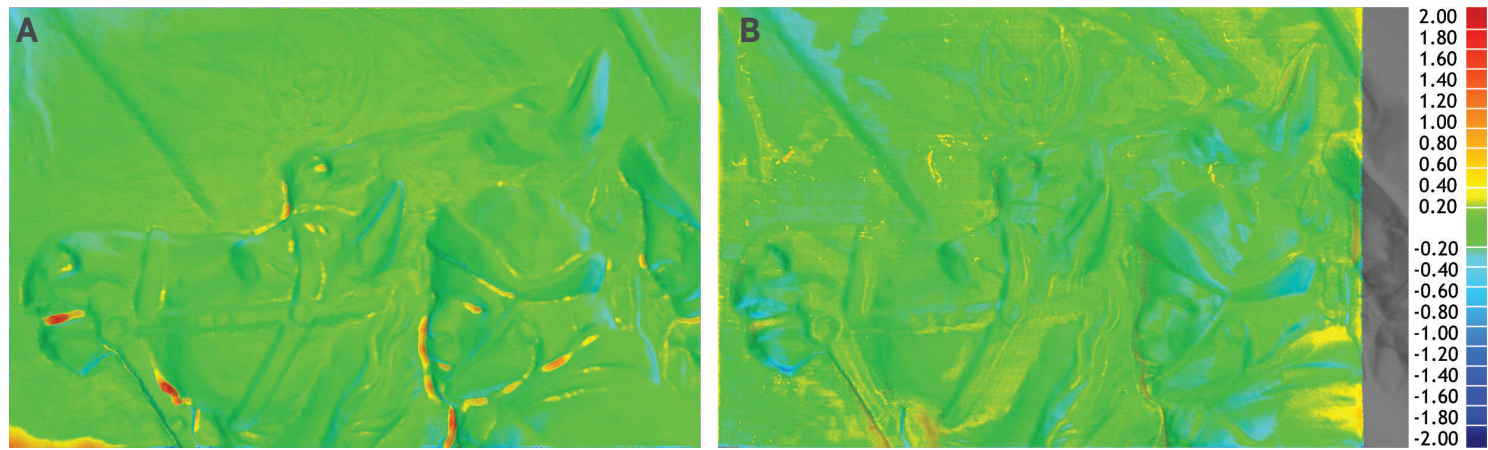

Figura 6: Análise dimensional das peças desenvolvidas na etapa de fabricação digital, escala em mm Peça produzida por usinagem CNC; B) Peça produzida por impressão 3D por FFF.

Fonte: Elaborado pelos autores.

$\mathrm{Na}$ análise dimensional da peça usinada (Figura 6A), é possível observar algumas regiões em tons avermelhados, ou seja, com maiores divergências dimensionais em relação ao modelo original. Essas áreas correspondem aos locais onde a ferramenta de usinagem não consegue penetrar o material para realizar o desbaste necessário ao detalhamento. A inserção de uma etapa adicional de acabamento com utilização de uma ferramenta de menor diâmetro permitiria a execução dos detalhes em questão. 
A peça impressa apresenta maior número de pontos com diferenças dimensionais em relação ao modelo digital da peça original. Apesar de serem diferenças dimensionais menores, elas estão espalhadas por toda a superfície da peça. Essas divergências correspondem, por exemplo, a áreas em tons azulados (lado esquerdo da peça) e em tons amarelados (lado direito), como é possível verificar na Figura 6B.

Visualmente, a peça usinada (Figura 7A) apresenta poucos pontos com rastros de ferramenta, porém, o acabamento superficial é mais uniforme do que o apresentado pelo processo de impressão 3D. Na peça impressa (Figura 7B), é possível observar as camadas da impressão, que deixam uma textura característica do processo, além dos erros já apontados na totalidade da superfície.

Considerando os resultados obtidos nas análises dimensional e visual, e que a ocorrência das principais divergências dimensionais na peça usinada poderiam ser evitadas com a inserção de uma etapa de acabamento fino, a peça usinada foi a selecionada para o desenvolvimento dos ensaios posteriores.
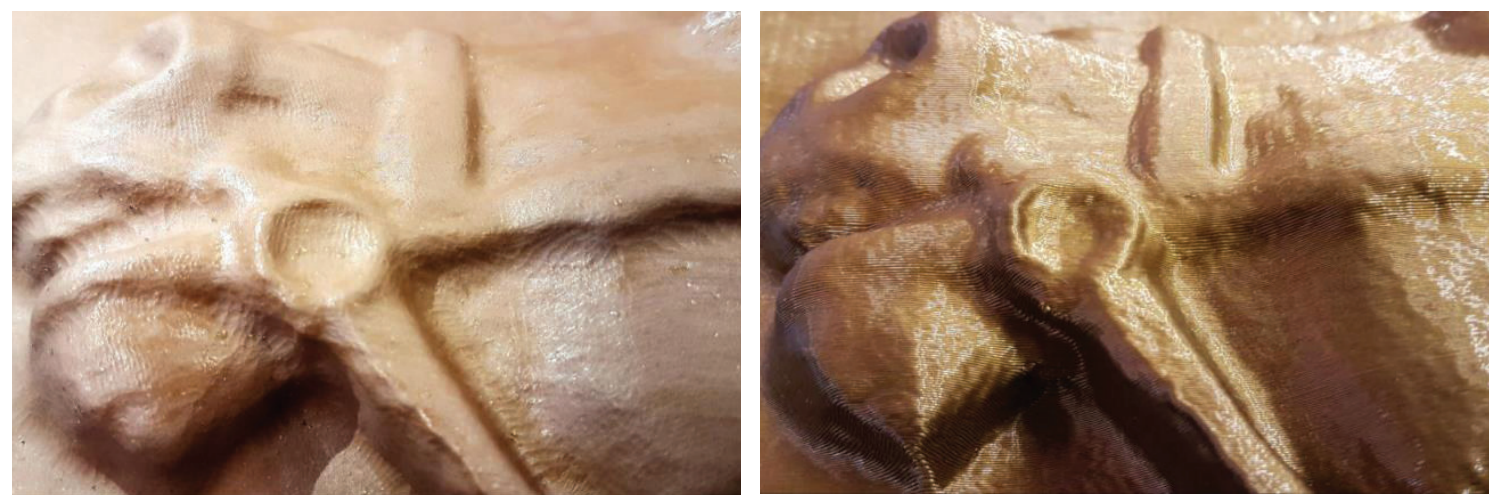

Figura 7: Detalhes das superfícies das peças fabricadas. A) Peça produzida por usinagem CNC; B) Peça produzida por impressão 3D por FFF.

Fonte: Elaborado pelos autores.

Utilizando a peça usinada como matriz, foi desenvolvido um molde em silicone para os ensaios subsequentes. As cinco réplicas produzidas por meio deste molde em três diferentes resinas foram digitalizadas para realização da avaliação dimensional (Figura 8). Os ensaios A e B correspondem às peças em poliéster cristal; os ensaios $\mathrm{C}$ e $\mathrm{D}$, às peças produzidas em resina epóxi; 0 ensaio E, à peça elaborada em resina de poliéster ortoftálica.

As moldagens em resina apresentaram as maiores divergências dimensionais dentre as etapas de fabricação e, além da contração do material, acumularam os erros dos processos anteriores. A Tabela 1, exibe os valores médios e desvios-padrão das diferenças captadas pela digitalização tridimensional nas peças produzidas para esse estudo.

A resina de poliéster cristal apresentou o melhor resultado dentre as resinas ensaiadas. 0 erro médio para este material foi de $0,68 \mathrm{~mm}$, enquanto a resina ortoftálica apresenta o maior erro médio que corresponde a 0,93 $\mathrm{mm}$. Os dois processos de fabricação digital exibem resultados próximos. Essa diferença baixa entre os erros médios pode ser explicada pelas dimensões das áreas com erros na peça e intensidade das divergências dimensionais. A peça usinada apresenta poucos pontos com erros, porém, são erros acentuados, enquanto o modelo impresso contém diversas áreas com erros leves espalhados por toda a superfície. 


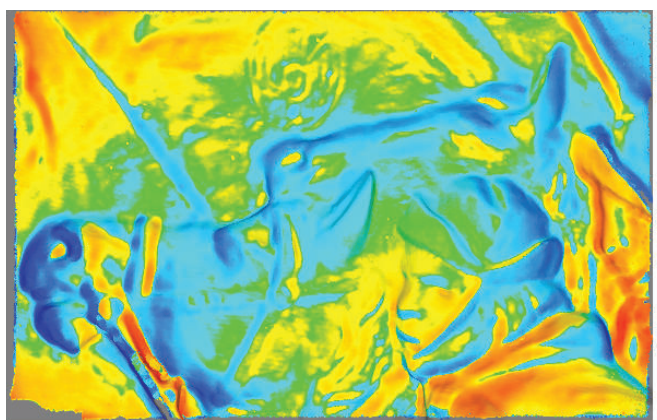

A

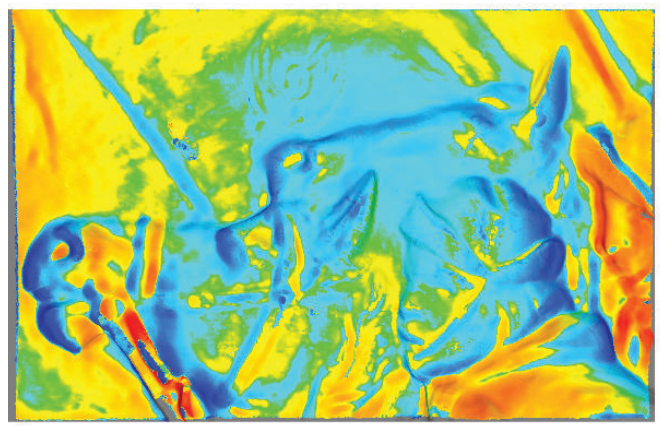

C

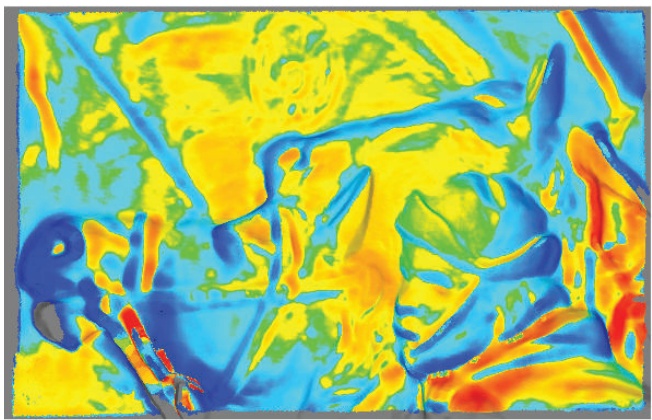

$\mathrm{E}$

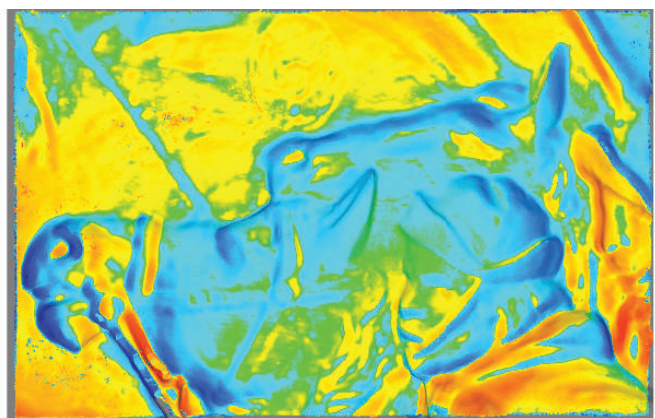

B

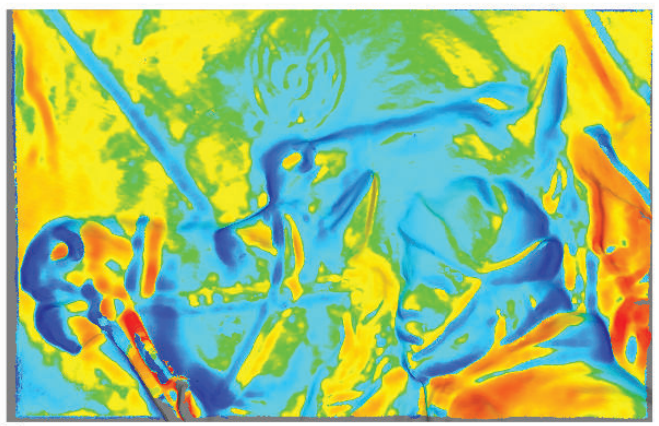

D

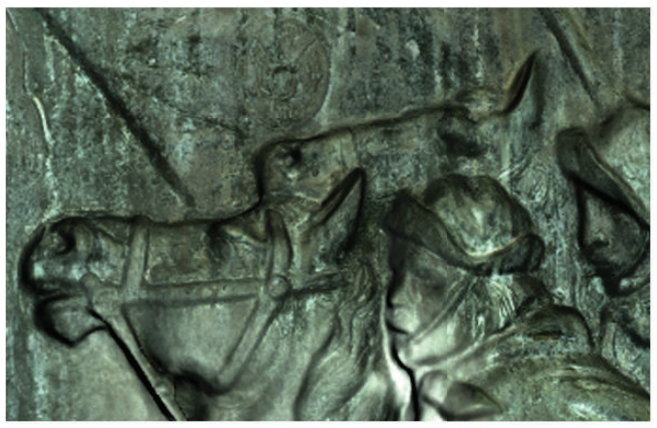

$\mathrm{F}$
2.00

1.80

1.60

1.40

1.20

1.00

0.80

0.60

0.40

0.20

0.00

$-0.20$

$-0.40$

$-0.60$

$-0.80$

$-1.00$

$-1.20$

$-1.40$

$-1.60$

$-1.80$

$-2.00$

Figura 8: Análise dimensional dos ensaios realizados com resinas, escala em mm. A) Poliéster cristal 1; B) Poliéster cristal 2; C) Resina epóxi 1; D) Resina epóxi 2; E) resina de poliéster ortoftálica; F) Modelo 3D.

Fonte: Elaborado pelos autores.

\begin{tabular}{c|c|c|c|c|c|c|c|c} 
& $\begin{array}{c}\text { Usinagem } \\
\text { CNC * }\end{array}$ & $\begin{array}{c}\text { Impressão } \\
\text { 3D por } \\
\text { FFF * }\end{array}$ & $\begin{array}{c}\text { Molde } \\
\text { de } \\
\text { silicone }\end{array}$ & $\begin{array}{c}\text { Resina de } \\
\text { poliéster } \\
\text { Cristal 1 }\end{array}$ & $\begin{array}{c}\text { Resina de } \\
\text { poliéster } \\
\text { Cristal 2 }\end{array}$ & $\begin{array}{c}\text { Resina } \\
\text { de epóxi } \\
\mathbf{1}\end{array}$ & $\begin{array}{c}\text { Resina } \\
\text { de epóxi } \\
\mathbf{2}\end{array}$ & $\begin{array}{c}\text { Resina de } \\
\text { poliéster } \\
\text { ortoftálica }\end{array}$ \\
\hline Média & 0,07 & 0,08 & 0,29 & 0,68 & 0,67 & 0,72 & 0,72 & 0,93 \\
\hline Desvio- & 0,10 & 0,10 & 0,40 & 0,88 & 0,85 & 0,96 & 0,97 & 1,08 \\
padrão & 0,10 & & & 0,07 & &
\end{tabular}

* As peças foram moldadas a partir da usinagem CNC, a impressão 3D é apresentada a título de comparação.

Tabela 1: Resultados das análises dimensionais, dimensões em mm

Fonte: Elaborado pelos autores. 


\section{CONCLUSÕES}

A partir da digitalização tridimensional, demonstrou-se a possibilidade de produzir uma peça por fabricação digital (usinagem CNC e impressão 3D) com tolerâncias dimensionais médias menores do que 0,1 $\mathrm{mm}$. No caso de utilizar esses processos para produzir moldes, demonstrou-se a possibilidade de obter peças moldadas em resinas com tolerâncias médias de aproximadamente $0,7 \mathrm{~mm}$.

Apesar de permitir a reprodução de algumas formas geométricas mais complexas do que a usinagem CNC, o acabamento superficial da impressão 3D possui uma textura característica da tecnologia FFF. Assim, concluiu-se que a usinagem CNC é mais adequada para a produção de superfícies como as placas estudadas neste trabalho. Cabe considerar que para o caso de outras formas, como bustos, a impressão 3D pode apresentar vantagens e novos estudos podem ser realizados nessa direção.

Destaca-se que é viável tecnicamente a produção da placa inteira por usinagem $\mathrm{CNC}$ em diferentes materiais. A questão a ser considerada para a execução de uma peça em tamanho real reside no aspecto econômico. Por outro lado, grande parte das impressoras atuais, em especial as disponíveis no Brasil, ainda apresentam limitações de tamanho, materiais e tempo de processo para produção de peças de maior porte. Embora, cada vez mais, novos materiais venham sendo desenvolvidos para as impressoras 3D FFF, ainda não são muitos materiais disponíveis e há uma dificuldade em ajustar as propriedades às necessidades de resistência a intempéries, especialmente para peças que sejam expostas ao ar livre.

Para a produção de uma réplica fidedigna, há de se considerar outras características importantes, além da precisão dimensional, tais como cor, durabilidade e custo. Nesse sentido, a moldagem em resinas permite a utilização de aditivos, por exemplo, para resistência ao ultravioleta, ou pigmentos para ajuste da coloração da peça. Cabe destacar que a qualidade da peça final será determinada em função dos materiais utilizados como modelos e moldes nas etapas subsequentes à fabricação digital.

Todas as resinas ensaiadas neste trabalho apresentaram uma certa contração, porém, a peça que apresentou menor quantidade de erros foi a produzida em poliéster cristal. Assim, essa é a melhor opção, dentre as resinas ensaiadas, para o desenvolvimento de uma réplica fidedigna. A inserção de pó de bronze a essa resina e a realização de tratamento superficial pode ser uma estratégia para a reposição das peças originalmente compostas em bronze, evitando, dessa forma, novas ações de furto.

\section{REFERÊNCIAS}

ADAMI, A. et al. The bust of Francesco II Gonzaga: from digital documentation to 3D printing. ISPRS Annals of the Photogrammetry, Remote Sensing and Spatial Information Sciences, V. II-5/ W3, p. 9-15, 2015. Trabalho apresentado no 25 International CIPA Symposium, 2015, Taipei. doi: 10.5194/isprsannals-II-5-W3-9-2015

ALVES, José Francisco. A escultura pública de Porto Alegre: história, contexto e significado. Porto Alegre: Artfolio, 2004.

BALLARIN, M.; BALLETTI, C.; VERNIER, P. Replicas in Cultural Heritage: 3D Printing and the Museum Experience.
International Archives of the Photogrammetry, Remote Sensing \& Spatial Information Sciences, V. XLII-2, p-55-62, 2018. Trabalho apresentado no ISPRS TC || Mid-term Symposium "Towards Photogrammetry 2020”, 2018, Riva del Garda. doi: 10.5194/isprs-archives-XLII-2-55-2018

BALLETTI, Caterina; BALLARIN, Martina; GUERRA, Francesco. 3D printing: State of the art and future perspectives. Journal of Cultural Heritage, v. 26, p. 172182, 2017. doi: 10.1016/j.culher.2017.02.010

BEAUBIEN, Harriet F.; KARAS, Vicky Basiliki. 3D scanning of deer stones on the Mongolian steppe. Objects Special- 
ty Group Postprints, v. 14 , p. 178-196, 2007.

BENEDETTI, Verônica. Os procedimentos técnicos de revitalização. In: ALVES, José, Franscisco. (Org.). Resgate do patrimônio histórico: construção cultural Parque Farroupilha. Porto Alegre: Associação Sul Riograndense da Construção Civil, 2016. p. 13.

D'AGNANO, F.; BALLETTI, C.; GUERRA, F.; VERNIER, P. Tooteko: A case study of augmented reality for an accessible cultural heritage. Digitization, 3D printing and sensors for an audio-tactile experience. The International Archives of the Photogrammetry, Remote Sensing and Spatial Information Sciences, v. XL-5/ W4, p. 207-213, 2015. Trabalho apresentado no 3D Virtual Reconstruction and Visualization of Complex Architectures, 2015, Avila. doi: 10.5194/isprsarchives-XL-5-W4-207-2015

ESTÁTUA de Bento Gonçalves é novamente furtada na Capital. Bandeirantes. Porto Alegre, 3 maio 2017. Disponível em: https://noticias.band.uol.com.br/ cidades/ rs/noticias/100000856410/ estatua-de-bento-goncalves-e-novamente-furtada-na-capital.html. Acesso em: 2 jun. 2017

FRAZÃO, Mateus. Furtos em sequência de monumentos e placas em Caxias mostram descaso com o patrimônio. Pioneiro. Caxias do Sul, 09 ago. 2018. Disponível em: http://pioneiro. clicrbs.com.br/rs/geral/noticia/2018/08/ furtos-em-sequencia-de-monumentos-e-placas-em-caxias-mostram-descaso-com-o-patrimonio-10532224.html. Acesso em: 26 out. 2018.

VARGAS, Bruna. Ladrões furtam segundo painel de monumento a Bento Gonçalves em Porto Alegre. GaúchaZH. Porto Alegre, 2 maio 2017. Disponível em: https://gauchazh.clicrbs.com. br/porto-alegre/noticia/2017/05/ ladroes-furtam-segundo -painel-demonumento-a-bento-goncalves-emporto-alegre-9784809.html. Acesso em: 2 maio 2017.

LEVOY, M. et al. The digital Michelangelo project: 3D scanning of large statues. In: Annual Conference on Computer Graphics and Interactive Techniques, 27, 2000, New Orleans. Anais [...]. New York: ACM Press/Addison-Wesley Publishing Co., 2000. p. 131-144. doi: $10.1145 / 344779.344849$

MUNIZ, Guilherme Resende; SILVA, Fabio Pinto da; KINDLEIN JÚNIOR, Wilson.
Design, tecnologia e patrimônio: digitalização tridimensional como ferramenta de preservação de elementos de prédios históricos. Gestão \& Tecnologia de Projetos, v. 13, n. 2, p. 53-66, 2018. doi: 10.11606/gtp.v13i2.138358

REYS, Aranda Cailó dos; LAMA, Eliane Aparecida Del; DEHIRA, Lauro Kazumi. Monumentos da Cidade de São Paulo: formas de alteração e conservação. Revista CPC, v. 5, p. 93-122, 2008.

ROSSETTI, V. et al. Enabling Access to Cultural Heritage for the visually impaired: an Interactive 3D model of a Cultural Site. Procedia Computer Science. v. 130, p. 383-391, 2018. Trabalho apresentado no 9o International Conference on Ambient Systems, Networks and Technologies, 2018, [Porto]. doi 10.1016/j.procs.2018.04.057

SPALDING, Walter. Pequena história de Porto Alegre. Porto Alegre: Sulina, 1967.

TILL, Rodrigues. Monumentos de Porto Alegre - Ensaio histórico e crítico. Porto Alegre: Evangraf, 2002.
Carolina de Freitas Bonfada carolinabonfada@hotmail.com

Aline Reis Kauffmann aline.kauffmann@ufrgs.br

Fabio Pinto da Silva fabio.silva@ufrgs.br 